\title{
Training of Mathematics Teachers in a South African University \\ Nolutho Diko
}

\author{
North West University (MC), South Africa \\ Email: Nolutho.Diko@nwu.ac.za \\ Nosisi Feza \\ Institute of Science and Technology Education, University of South Africa \\ Email: Fezann@unisa.ac.za
}

\section{Doi:10.5901/mjss.2014.v5n23p1456}

\section{Abstract}

The research reported in this paper examined the types of knowledge prioritized in two mathematics teacher training programmes in a South African university. To do this, focus was placed on the time spent training the future teachers in mathematics content knowledge, mathematics pedagogy knowledge and general pedagogy knowledge. Teacher trainees' surveys and institutional surveys and other programmatic material available online and at the university provided data that described the two teacher training programmes: the general education and training and the further education and training programmes. Descriptive analysis of teacher trainees' surveys and institutional surveys were also conducted. The findings revealed that the amount of time spent on mathematics content, mathematics pedagogy and general pedagogy in training teacher trainees and related programmatic characteristics is related to the proficiencies teacher trainees exit with from their preparation programmes.

Keywords: Mathematics teacher education, teacher education policies, teacher knowledges

\section{Introduction}

According to one of the most published international teacher education experts, Linda Darling-Hammond (2000), policy investments in the quality of teachers may be related to improvements in student performance. A South African team of experts on teacher quality confirmed this, and commented that not all South African teachers of mathematics have the required levels of skills for the classes they teach, hence the low learner pass rates in mathematics (Taylor et al., 2012) Since 2009, South Africa has prioritized education as a national project. The current Presidency has five priority areas and education is the foremost of these with the greatest budget allocation. Despite the attention enjoyed by education, there are concerns that the returns on investment are low as learners keep on performing poorly in assessment after assessment, especially in areas such as numeracy or mathematics, and literacy or languages (Taylor et al., 2012; TIMSS, 2011; Bernstein, 2013; Murtin, 2013). The preparation of mathematics teachers is a concern for countries whose intention it is to improve how their learners perform in international assessments, including South Africa.

Mathematics scores always leave researchers and policymakers wondering how to improve the results. They are always interested in finding out how they can improve teaching and learning of mathematics. In 2011, five South African universities undertook a study to investigate the opportunities to learn (OTLs) provided to BEd mathematics teacher trainees in the General Education and Training (GET) and the Further Education and Training (FET) programmes in each of these universities. Opportunities to learn were measured by the time spent on training the future teachers. The research was a collaborative work between researchers form the Human Sciences Research Council (HSRC), researchers from Michigan State University in the United States as well as researchers from five South African universities. At that point, the researchers from Michigan had just completed the Mathematics Teaching for the $21^{\text {st }}$ Century (MT21) study, which was a six country empirical investigation into the preparation of intermediate and senior phase mathematics teachers in Germany, United States, Bulgaria, Mexico, Taiwan and Korea. This paper is a small portion of that study which is reported by Diko and Feza (2014). Here, the focus is only on one of the five South African institutions of higher learning that were studied. 


\section{Problem Statement}

Mastery of mathematics and technology is an important skill for this era. Poor mathematics performance is not desirable and is a problem. South Africa has a serious problem of poor mathematics teaching and learning. Adler and Reed (2002) posit that poor mathematics knowledge in South African teachers is rooted in the apartheid teacher education. Hofmeyr and Hall (1995) also noted this problem of poor subject knowledge. After conducting a national teacher education audit they reported that under apartheid students acquired superficial knowledge of their teaching subjects. Almost 20 years thereafter, with significant policy changes in place, including the Minimum Requirements of Teacher Education Qualifications policy (2008), the National Education Evaluation and Development Unit (2012) led by Nick Taylor, Taylor who also had been part of the National Teacher Education Audit in 1995, concluded that despite being appropriately qualified, as per the requirements of the Department of Higher Education, the majority of South African teachers still had poor subject knowledge.

A different report written by Anne Bernstein for the Centre for Development and Enterprise (CDE, 2013) recently confirmed that there is poor teaching of mathematics in public schools. This deficiency is translated to poor mathematics teaching and learning and confirmed by poor learner performance in most national and international assessments. Even though results from the Trends in South African Mathematics and Science Study (TIMMS; 2011) show an improvement in achievement scores of the $8^{\text {th }}$ and $9^{\text {th }}$ graders from those of TIMMS (2003), as well as improvements in the end of the year grade twelve results, overwhelming evidence indicates that South Africa ranks at the bottom of the international spectrum. Murtin (2013), in a report prepared for the Organisation for Economic Co-operation and Development (OECD), says that a large fraction of students, especially Africans, do not reach basic qualification standards in mathematics. In the CDE report, Bernstein correctly agrees with the OECD report and further concludes that much needs to be done in relation to the mathematical and pedagogical knowledges of teachers; without knowing how these knowledges are developed, nothing can be done, however.

\section{Structure of the Paper}

The purpose of this article is to report on the research done in terms of one of the South African institutions of higher education mentioned above. In order for it to meet its purpose, the remainder of the article is structured as follows. The next section contains the conceptual and theoretical framework on which the investigation was based. The section thereafter explains the research design and approach. Following hereon is a section aiming at presenting and analyzing the findings together with the discussion. The final section contains some recommendations.

\section{Conceptual and Theoretical Framework}

\subsection{Opportunities prioritized by teacher education programmes}

Schmidt et al (2011) encourage understanding of characteristics of teacher education programmes that may influence the development of teachers' professional competence. They say that such characteristics include selectivity, time allocated, programme content, teaching methods, characteristics of teacher educators, and so on. Drawing attention to this challenge of the characteristics of training programmes and their effect on the quality of teachers produced, Adler (1994) says that the training of mathematics teachers under apartheid provided the trainees with very few opportunities to learn mathematics content knowledge (MCK) and mathematics pedagogic content knowledge (MPCK). Instead, because teachers were inadequately prepared, mathematics teaching employed the "Tell and drill" approach (p.104).

The post-apartheid government made many policy changes in order to raise the levels of teaching and teachers, among others the Norms and Standards for Educators Policy (NSE) of 2000 which was later replaced by the National Qualifications Framework Act 67 of 2008 policy on the Minimum Requirements for Teacher Education Qualifications (MRTEQ). According to the requisites in these two policies, mathematics teacher education programmes are required to prioritize teachers' mathematical knowledge and practices. The policies give the ratios and mixes of knowledges universities are expected to follow when designing their programmes and planning the experiences to be provided to trainees and the amount of time to be spent on each of the areas of training. We return to this issue below.

Emphasizing one type of knowledge at the expense of the other is risky. Shulman's works (1985, 1986, and 1987) emphasize the importance of keeping the correct balance between content and pedagogical knowledge in teaching. An HSRC study on student achievements (Chisholm et al., 2009) also emphasizes the importance of getting the mixes between content knowledge and pedagogical knowledge right. They report that one of the causes of poor mathematics 
learner achievements is the ratios universities employ in their knowledge mixes. Blömeke et al. (2011) compared mathematical content knowledge (MCK) scores of high performing countries with their mathematics pedagogical knowledge (MPK) scores and concluded that the scores indicate interdependence between mathematics content knowledge and mathematics pedagogical knowledge. Both MCK and mathematical pedagogical content knowledge (MPCK) are important knowledges. Mathematics content knowledge on its own is not enough. It is helpful to teachers only up to a certain point (Schmidt et al., 2011). Darling-Hammond (2006) underscores this point by saying that there is a range of abilities that teachers need to possess in order to successfully teach all kinds of students in today's classes. Teacher training programmes therefore need to make sure that training programmes cohere and are tightly integrated for effectiveness (Feza \& Diko, 2013).

\subsection{Becoming a teacher in South Africa}

Under apartheid, there were no uniform qualifications, structure or standards and norms to provide guidelines about how to train teachers (Parker, 2003). In the post-apartheid era the government rationalized qualifications and provided guidelines for teacher training, including how much time can be spent in each of the different types of knowledges. To be qualified, teachers must get a four year degree from a university. The National Qualifications Framework Act 67 of 2008 and the MRTEQ policy stipulate that becoming a teacher in South Africa follows strictly one of the two was; completing a four year Bachelor of Education (BEd) degree, which consists of 480 credits including a practical component of 120 credits at level 7, or completing an appropriate first degree followed by a one-year Advanced Diploma in Education. The policy introduces competencies that a trained competent teacher must possess; a BEd degree must lead to the development of those. Graduates are also expected to demonstrate knowledge and skills in their particular phase/s and or specialization/s as well as practical skills and workplace experience to teach in varying contexts.

The NSE and recently the Minimum Requirements of Teacher Education Qualifications policy mandate universities to construct teacher education programmes and modules that are consistent with teacher policies and institutional goals. According to these policies, the courses offered in teacher education programmes must subscribe to the following thematic areas:

Disciplinary learning - which refers to disciplinary or subject matter knowledge or the study of education and its foundations and specific specialized subject matter.

Pedagogical learning - this includes general pedagogical knowledge and specialized pedagogical knowledge.

Practical learning or Work-integrated Learning (WIL) - this involves teaching in authentic and simulated classroom environments.

Fundamental learning - this means learning to converse competently in second language, to use information and communication technologies competently.

Situational learning - this refers to the knowledge of the varied learning situations, contexts and environment as well as the prevailing policy, political and organizational contexts.

For quality assurance, the South African qualifications authority has introduced the concept of credits and notional time as a means to assist universities to plan and calculate student workload. One credit is equal to ten notional hours of learning. At the end of training, trainees must have achieved a minimum credits of 480 credits to get the four year BEd degree. At least $50 \%(240 \mathrm{C}$ ) of these credits must focus on developing the teaching specialization phase or subjects, including subject-focused disciplinary, pedagogical and practical learning. 40\% (192 C) must be spread across educationally-focused disciplinary learning and the remaining 10\% (at most $48 \mathrm{C}$ ) may be used flexibly, for example, to strengthen teaching specialization or to enhance a student's success for studying at tertiary level. The knowledge mixes of programs must also subscribe to the level of learning stipulated by SAQA and the Higher Education Qualifications Council (HEQC).

\subsection{Mathematics teacher education in South Africa}

According to the policy requisites discussed above, universities offering mathematics teacher education must see to it that they prioritize teachers' mathematical knowledge, and pedagogic practices. Graven (2005) rightfully cautions that there is the dilemma of selection and integration of knowledge and practice in the area of mathematics teacher education. Adding to this, in her plenary paper in Namibia, in 2005, Adler asserted that the unpacking of mathematics "is not well understood and too hard to do in the context of formalized teacher education" (p.14). She says this is problematic because demands made by the educational reform initiatives aim to construct a new pedagogic identity in teachers (Parker, 2005: 2). 
In Chuene's (1999) study on South African student teachers' views on mathematics teaching another challenge that surfaced was that according to students' perspectives, training provided by institutions of higher education seems not to prepare mathematics teachers sufficiently for school realities. Chisholm et al. (2009), in a HSRC report on understanding student performance, similarly exposed the challenges of South Africa's mathematics teacher preparation. Expanding on the diverse nature of the opportunities universities provide to trainee teachers, they go on to say that universities employ a variety of ratios, ranging from a purely mathematical content to a ratio which focuses more on methodological and pedagogical content in relation to the teaching of mathematics. The extent to which faculties link their teaching to the school mathematics curriculum (NCS) varies too. Some institutions teach only the mathematics which the teachers themselves would teach at the phase level in a school (Chisholm, et al. 2009). Criticizing this approach, the Chisholm study says that such an approach does not deepen or extend teachers' own knowledge and mathematics sufficiently to equip them to teach learners at the phase level.

\subsection{Good practices from international preparation of mathematics teachers}

Teacher training policies differ from one country to another and sometimes they differ even within the same country. Most countries train teachers over 4 years but other countries take longer than 4 years, for example, Taiwan and Germany. Taiwanese programmes are among the most intense. Teacher trainees cover more topics than their counterparts in other countries, especially difficult topics. Schmidt et al. (2011), after studying training of mathematics teachers in six different countries, reported that training differentials are based on content as well as on the clock hours. The German teacher education system is the longest in Europe (OECD, 2004) and the teacher preparation program is rigorous and inflexible (Ladd, 2007; Schmidt et al. 2011). German teachers have a solid foundation in subject matter studies, which they study in the university departments specializing in the respective subjects. In Korea, applicants for teacher education programmes are required to have mathematics scores that are higher than those of applicants for fields like medicine. Korean mathematics teacher preparation consists of four key areas: mathematics, mathematics pedagogy, general pedagogy and liberal arts courses. Teaching is favored by Korean youth (Ingersoll, 2007: 55). Obviously, teacher trainees get different exposures in teacher training programs.

\section{Research Design and Methodology}

A case study approach was employed with a view to understand how the institution, referred to as institution 1, enhanced its GET and FET mathematics teacher preparation programmes. We examined institution 1's teacher education curriculum with a view to understand how the programmes enhance the preparation of trainee teachers. We attempted to answer one important question: Given that the quality of South African mathematics teachers has been considered poor and in need of improvement, how is the preparation of future mathematics teachers geared towards producing capable GET and FET teachers?

The principal data sources for this paper were teacher trainee surveys collected from the students and the teacher education administration. Data collected were limited to:

- Institutional/Expert surveys. This was a lengthy and detailed form used to collect program specific information from programme management and administration.

- Teacher trainee surveys. This was another lengthy and detailed form used to obtain information from $1^{\text {st }}$ and $4^{\text {th }}$ year teacher trainees' in the general education and training (GET) and further education and training (FET) programmes.

The $1^{\text {st }}$ year cohort was used to obtain baseline information about what the trainees knew when they first joined the institution. The $4^{\text {th }}$ year cohort was used to obtain information about what the trainees knew at the end of their 4 year training. 294 students responded to the surveys. Of this number, 176 were $1^{\text {st }}$ years and 118 were $4^{\text {th }}$ years. Institutional or programmatic matters were combined and addressed in one form. How the institution handled the various management and administrative issues required by the form was up to the institution. One or more than one institutional representative could respond to the survey.

From the data collected, information was selected related to what the trainees learn from the opportunities the mathematics programmes create and provide to them. In doing this, our specific intention was to assist the university to understand and improve its programmes. The information categories in the questionnaire included demographics and academic background, academic learning opportunities, beliefs and perspectives on schooling, mathematics teaching and learning of grades $4-12$ learners and knowledge items related to the teaching of mathematics. The focus of the achievement items was on the mathematics' fundamental topics normally taught at the lower and upper secondary levels 
across some 40 countries. The topics included were algebra, functions, number geometry and statistics.

\section{Findings}

\subsection{Policy guidelines on organization of coursework and time allocation}

In South Africa, teacher education policies are enacted at the national government level and implemented at the institutional level. Universities adopt the policies and adapt them to suit the institutional goals. Fundamental to the South African 4 year BEd programmes are the following themes: disciplinary learning, pedagogical learning, practical learning or work-integrated learning (WIL), fundamental learning and situational learning mixed according to the minimum stipulated ratios or more.

Another significant aspect of teacher preparation is the concept of credits and notional time which determines parameters with regards to the amount of academic work and the practical experiences universities can and must provide. The policy prescribes that to graduate trainees must achieve the same minimum credits or time (notional hours) for a BEd programme, which are 480 credits (C) or 4800 hours. Of the 4800 hours, at least $50 \%$ or 2400 hours must focus on developing the teaching specialization subjects, including subject-focused disciplinary, pedagogical and practical learning. At least 40\% (1920 hours) must be spread across educationally-focused disciplinary learning and the remaining $10 \%$ or 480 hours may be used flexibly. During the four years of training students must spend 20-32 weeks doing school based supervised practice teaching. The policy provides a broad outline of how much time can be spent on an area and allows universities leeway to decide on the specifics of how much time to spend on each area. Below we discuss how institution 1 has implemented the policy described above.

\subsection{Admission requirements into teacher preparation at institution 1}

Applicants seeking to be admitted to study undergraduate degree programmes in institution 1 must be in possession of a National Senior Certificate for Degree Studies or a Senior Certificate with endorsement. Admission is based on the minimum university determined academic performance score (APS). BEd students must obtain at least 24 out of the possible 32 points in order to be admitted to teacher education programmes. Furthermore, applicants must meet the required level of performance per subject. Prospective FET mathematics major students are required to obtain a 50\% pass in grade 12 mathematics.

\subsection{Credit and time allocations per knowledge area for each programme}

\subsubsection{GET Programme}

Institutions have different expectations about the intensity and duration of learning experiences. Coursework and credits taken over the preparation period can vary too (Schmidt et al (2011). GET trainees in this institution are expected to complete a minimum of 512 credits or 5120 hours credits to graduate, taking a minimum of $32 \mathrm{C}$ or 320 hours more than the national requirement. Figure 1 below gives a diagrammatic representation of the GET course distributions.

Mathematics content is allocated the least time. It has $64 \mathrm{C}$ which translates to the equivalent of 640 hours over four years. That comprises $12.5 \%$ time spent on learning mathematics content during the entire training period. Mathematics pedagogy is allocated slightly more time at $72 \mathrm{C}$ or 720 hours of learning over four years. This means $14.06 \%$ of the entire training period that is spent on learning mathematics pedagogy. General pedagogy is assigned even more time than the other two at $168 \mathrm{C}$ transferring to 1680 hours. This is $25.5 \%$ of the time which is spent on learning general pedagogy. Of the 168 credits 32 credits or 320 hours are set aside for practice teaching. This means $6.25 \%$ of the entire time.

This university takes advantage of the flexi-time provided for by the policy as it uses 24 of those credits transferring to 240 hours for optional basic mathematics content knowledge. This option is for helping students who did not do mathematics in their high school certificate to build their mathematics base up. The remaining credits of 184 (35.9\%) translated to 1840 hours are spent on skills such as language and literacy, communication or Afrikaans, natural science learning area and technology, life skills and arts and culture learning area studies. 


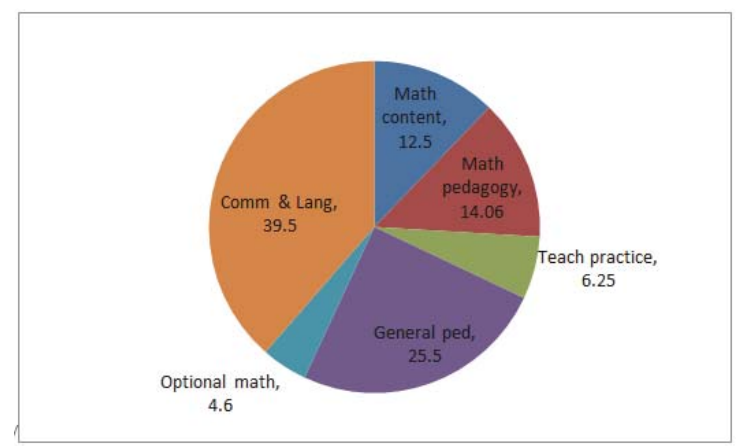

Figure 1: GET course distribution

\subsubsection{FET Programme}

Just like the GET programme, the credit hours for this degree are more than the stipulated $480 \mathrm{C}$ for a BEd degree at 540 $\mathrm{C}$ or 5400 notional hours. FET teacher trainees receive 60 more credit hours than the policy requirements. FET students have more than one specialization; we will only focus on mathematics and ignore the other specializations.

The allocations are as follows: mathematics content $128 \mathrm{C}$, mathematics pedagogy $48 \mathrm{C}$, general pedagogy 144 and the other groups share 220 . When translated to percentage points, the trainees spend $23.7 \%$ learning mathematics content knowledge, $8.8 \%$ learning mathematics pedagogy knowledge, $22.2 \%$ of general pedagogy, $4.4 \%$ on teaching practice, and $6.6 \%$ on extra learning areas and the last $7.7 \%$ of the training time is spent on computer literacy and communication skills. Figure 2 below gives a visual display of this distribution for FET student teacher course taking time.

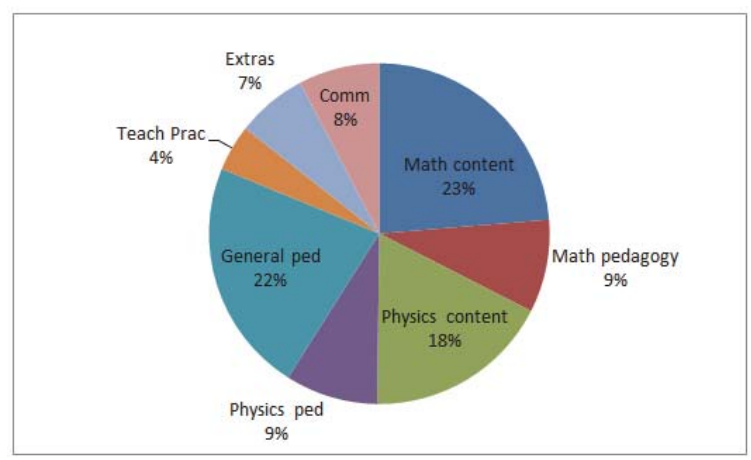

Figure 2: FET course distribution

When the four areas are examined comparatively, one sees that general pedagogy gets more time than mathematics content with mathematics pedagogy getting even less time. Teaching practice gets the least time in both programmes. This allocation, which puts less emphasis on pedagogical knowledge and practical knowledge, raises concern about the competency of graduates who will come out of such a model.

\section{Provision of Different Types of Knowledges}

\subsection{GET Content knowledge}

Figure 3 below indicates that $1^{\text {st }}$ year GET teacher trainees' algebra, functions, geometry and number knowledge mean scores are better than $4^{\text {th }}$ years in the same programme. However, there is no significant difference in data and probability of the same group of teacher trainees. 


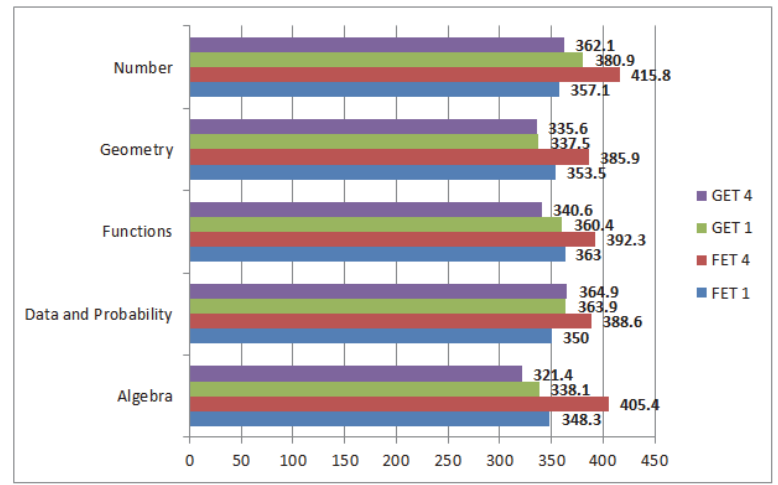

Figure 3: Mathematics content knowledge

\subsection{FET content knowledge}

The mathematics content knowledge of the FET trainees increased over the four year period. Fourth year teacher trainees performed better than first years. This reflects positively on their course taking. FET trainees are offered more mathematics content knowledge courses than content pedagogy and general pedagogy courses. However, it is important to note that the knowledge tested was relevant for Senior Phase teacher trainees.

\subsection{GET mathematics pedagogy knowledge}

There is no significant difference on the mathematics pedagogy knowledge for $1^{\text {st }}$ year GET and $4^{\text {th }}$ year GET students. Pedagogic knowledge is specialized. It cannot be acquired outside of teacher training programmes (Schmidt et al. 2011).

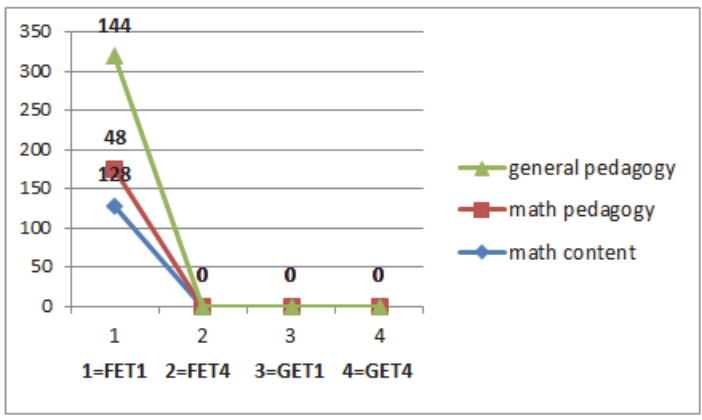

Figure 4: Mathematics pedagogy knowledge

\subsection{FET mathematics pedagogy knowledge}

FET teacher trainees exit with a significant improvement on their mathematics pedagogy knowledge. After 4 years of training, they show more knowledge compared to when they came in for their first year. Seemingly, the FET programme of institution 1 provides FET teacher trainees with more knowledge on how to teach mathematics compared to the GET programme.

\subsection{GET and FET general pedagogy knowledge}

As previously explained, this area shows gains in both the GET and the FET programmes. 


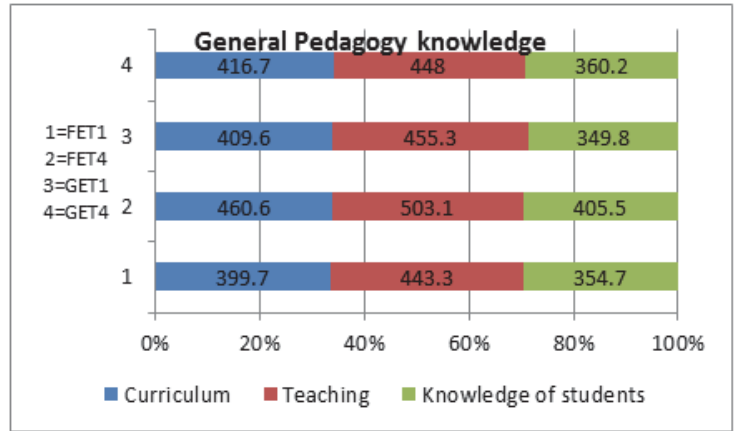

Figure 5: General Pedagogy Knowledge

\section{Discussion}

The emphases of institution 1's mathematics teacher training programmes vary. For example, the knowledge mixes for institution A's GET programme favor general pedagogy as it is allocated the most time, followed by mathematics pedagogy with the least amount of courses set for mathematics content. The university has a number of courses set aside for use to build the mathematics content base of students who did not do mathematics in high school. This means that students who obtained good mathematics scores in Grade twelve can spend their entire training time without studying mathematics if they are in the GET programme. It also means that students with poor Grade 12 mathematics pass scores can be accepted in the programme. The allocation of courses indicates that the GET programme still prioritizes general pedagogy. Clearly, even though the MRTEQ policy is new, the university has not deviated much from the apartheid policy of regarding MCK and MPK as less important than GPK for foundation phase teachers.

In the case of the FET programme, the allocations show an emphasis on mathematics content. However, according to the data FET teacher trainees spend little time learning how to teach mathematics compared with the time they spend on learning mathematics content and general pedagogy. Teaching practice receives the least time in both programmes. This allocation which puts less emphasis on pedagogical knowledge and practical knowledge raises a concern about the competency of graduates who are produced from such a model. The application and implementation of the teacher policies indicate strong awareness of and responsiveness to policy requirements as well as debates about current teacher preparation models, especially about designing programmes that acknowledge the relationship between content and content pedagogy. Overall, the trainees receive more training time and credits than the minimum requirements stipulated by the policies. This time is used to strengthen the various areas of the programme including the three focused on here.

\section{Conclusion}

Courses offered and the opportunities offered in teacher education programmes must be thoroughly looked into. Results from both programmes show direct correlation between the inputs and outputs; where there are more inputs, outputs are increased. For example, general pedagogy which receives more time than mathematics content and mathematics pedagogy in both programmes shows more improvement compared to the other two areas. When the trainees entered in their first year they showed little understanding of general pedagogy but by the end of their training, they showed significant gains in this aspect. The GET programme shows poor mathematics content knowledge and poor mathematics pedagogy knowledge because there are fewer inputs in these two areas. However, the FET programme shows more increases than the GET programme in the said areas because inputs in all the FET areas are more than the GET inputs.

\section{Recommendations}

When designing teacher education programmes and planning opportunities to learn, those tasked with that function must be mindful of the programme mixes and their impact on the product. Both programmes show an increase in the outputs in the area of general pedagogy meaning that the model employed to teach this specialization is good and can be replicated. The content knowledge displayed by the GET final year students is worrisome. The knowledge students have in the beginning of their training must be used as a scaffold for harnessing and nurturing mathematics content knowledge. 
The lower level of mathematics content and pedagogic knowledge displayed by the $4^{\text {th }}$ year GET trainees has to be avoided through intelligent planning and programming. FET training in this institution leads to better mathematics knowledge, better mathematics pedagogy knowledge and better general pedagogy knowledge with general pedagogy showing significant improvement. However, since the study was intended for intermediate and senior phase trainees, further research using FET relevant content and pedagogic knowledges need to be conducted.

\section{References}

Adler, J. \& Reed, Y. (2002). Challenges of Teacher Development: An Investigation of Take-Up in South Africa. (Pretoria, Van Schalk). Bernstein, A. (2013). Mathematics outcomes in South African Schools: What are the facts? What should be done? CDE INSIGHTS. Retrieved from http://www.cde.org.za

Blömeke, S., Suhl, U., \& Kaiser, G. (2011). Teacher Education Effectiveness: Quality and Equity of Future Primary Teachers' Mathematics and Mathematics Pedagogical Content Knowledge. Journal of Teacher Education, 62, 154-171.

Carnoy, M., Chisholm, L., \& Chilisa, B. (2009). The Low Achievement Trap: Comparing schools in Botswana and South Africa. Cape Town: HSRC Press

Chuene, K. (1999). The views of pre-service and novice teachers on mathematics teaching in South African related to their educational experience. Educational Research, 41(1), 23-34.

Darling-Hammond, L. (2000). Teacher Quality and Student Achievement: A Review of State Policy Evidence. Education Policy Analysis Archives, 8(1). Retrieved from http://epaa.asu.edu/epaa/v8n1

Darling-Hammond, L. (2006). Constructing 21st-Century Teacher Education. Journal of Teacher Education. 57 (3). 300-314

Department of Education. (2000). Norms and Standards for Educators. National Policy Act (Act No. 27 of 1996). Pretoria. Department of Education.

Department of Higher Education and Training (2011). Policy on the Minimum Requirements for Teacher Education Qualifications, Pretoria, Department of Higher Education and Training.

Department of Basic Education. (2011). Report on the National Annual Assessment of 2011.

Pretoria: Department of Basic Education.

Feza N \& Diko. (2013). Building on using strengths of mathematics teacher education in South Africa. Global Research Journal on Mathematics and Science Education. 2(1) 34-49.

Graven, M. (2005). Dilemmas in the design of in-service education and training for mathematics teachers. In Vithal, R., Adler, J. \& Keitel, C. (Eds.) Researching mathematics education in South Africa. Cape Town: HSRC press.

Hofmeyr, J. \& Hall, G. (1995). The National Teacher Education Audit. Synthesis Report. Johannesburg: Edupol.

Reddy, V., Winnaar, L., Visser, M., Feza-Piyose, N., Arends, F., Prinsloo, C.H., Mthethwa,

M., Juan, A. \& Rogers, S. (2013). Highlights from TIMSS 2011 South Africa

Murtin, F. (2013). "Improving education quality in South Africa." OECD Economics Department Working Papers, No. 156, OECD Publishing.

NEEDU. (2011). National Report 2012. The State of Literacy Teaching and Learning in the Foundation Phase. Government Printers

Parker, D. (2003). Curriculum Landscapes - Recontextualizing mathematics teacher education in S.A. Paper presented at the Kenton Conference at Godini Spar, October 2003

Parker, D. and Adler, J. (2005) Constraint or catalyst: The regulation of teacher education in South Africa. Journal of Education. 36: 5978.

Parker, D., \& Adler, J. (2005). Constraint or catalyst: The regulation of teacher education in South Africa. Journal of Education. 36 : 57 78

SAQA (2012). Summary of qualifications registered as of February 2012. Retrieved by 12 January at http://www.saqa.org.za/show. asp?include=qualstds.html

Schmidt. W.H., Cogan, L., \& Houang, R. (2011). The Role of Opportunity to Learn in Teacher Preparation: An international Context. Journal of Teacher Education, 62, 138-153

Shulman, L.S. (1985). Paradigms and research programs in the study of teaching: A contemporary perspective. In M.C. Wittrock (Ed.). Handbook of research on teaching ( $3^{\text {rd }}$ ed, pp 3-36). New York: Macmillan

Shulman, L. S. (1986). Those who understand: Knowledge growth in teaching. Educational Researcher, 15(2), 4-14. Shulman, L. S. (1987). Knowledge and teaching: Foundations of the new reform. Harvard Educational Research, 57, 1-22.

Shulman, L.S. (1987). Knowledge and teaching: Foundations of the new reform. Harvard Educational Research, 57, 1-22 